\title{
Pozitif Ses Çıkartma Davranışının Öncülü Olarak İletişim Doyumu *
}

\author{
Communication Satisfaction As a Predictor of Positive Voice Behaviour
}

\author{
Dr. Öğr. Üyesi Emine ŞENER ${ }^{1}$, Dr. Öğr. Üyesi Fatih Ferhat ÇETINKKAYA ${ }^{2}$, Arş. Gör. Ayşe \\ Nurefşan YÜKSEL ${ }^{3}$, Arş. Gör. Yusuf AKKOCA ${ }^{4}$
}

\begin{abstract}
Özet
İletişim doyumu kavramı, iletişim ile memnuniyet arasındaki ilişki üzerine yapılan çok çeşitli araştırmalar sonucunda ortaya çıkmış bir kavram olup; artması çalışanların örgütsel düzeyde pozitif tutum sergilemesine katkıda bulunmaktadır. Bu çalışmanın amacı, iletişim doyumunun pozitif ses çıkartma davranışının bir öncülü olup olmadığını belirlemek ve bununla birlikte pozitif örgütsel davranış literatürüne katkı sağlamaktır. Bu çalışma açıklayıcı bir araştırma olup anket tekniği kullanılarak gerçekleştirilmiş̧ir. Çalışanların iletişim doyum düzeylerini tespit etmek amacıyla Downs ve Hazen'in geliştirdiği "İletişim Doyumu Ölçeği" ve pozitif ses çıkartma düzeylerini belirlemek amacıyla, Maynes ve Podsakoff 'un geliştirdiği ve Çankır tarafından Türkçe uyarlaması yapılan "Pozitif Ses Çıkartma Ölçeğì" kullanılmışıır. Uygulanan anketler sonucunda elde edilen veriler SPSS ile analiz edilmiştir. Pozitif ses çıkartma davranışının öncülü olarak nitelendirdiğimiz iletişim doyumu ile yapılan regresyon analizi sonucunda iletişim doyumunun, katılımcıların pozitif ses çıkartma davranışındaki \%79'luk değişimi açıkladığı tespit edilmiştir. Sonuç olarak, yoğun ve karmaşık bir örgüt yapısına sahip hastanelerde, örgütün çalışanlardan yüksek düzeyde fayda sağlamasının bir yolu olarak düşünülen pozitif ses çıkartma davranışının, bir örgüt kültürü haline getirilmesinin öncülü olarak; olumlu iletişim ikliminin yaratılması önerilmektedir.
\end{abstract}

Anahtar Kelimeler: Pozitif ses çıkartma davranışı, iletişim doyumu, örgütsel iletişim, hastane çalışanları, hastane iletişimi

\begin{abstract}
The concept of communication satisfaction is emerged as a result of various researches on the relation between communication and satisfaction and increases of it contributes to the positive attitude of employees at the organizational level. The purpose of this study is to determine whether communication satisfaction is the antecedent of positive voice behaviour and to contribute to the positive organizational behavior literature. This study was a descriptive study and was conducted using questionnaire method. In order to determine the level of communication satisfaction, "Communication Satisfaction Scale" developed by Downs and Hazen was used and to determine levels of positive voice behaviour, "Positive Voice Behaviour Scale" developed by Maynes and

\footnotetext{
* Bu çalışma, 1. Uluslararası 11. Sağlık ve Hastane İdaresi Kongresinde sunulan "Pozitif Ses Çıkarma Davranışının Öncülü Olarak İletişim Doyumu: Bir Kamu Hastanesi Örneği” isimli özetin genişletilmiş hali olup, Ahi Evran Üniversitesi Bilimsel Araștırma Projeleri Koordinasyon Birimince Desteklenmiștir. Proje Numarası: IIB.A4.17.003.

1 Ahi Evran Üniversitesi, İ̈B Fakültesi, esener@ahievran.edu.tr, Orcid ID: orcid.org/0000-0002-8903-1684

2 Ahi Evran Üniversitesi, İ̈B Fakültesi, ffcetinkaya40@gmail.com, Orcid ID: orcid.org/0000-0003-2263-0479

3 Ahi Evran Üniversitesi, İ̈B Fakültesi, ayse.bali@ahievran.edu.tr, Orcid ID: orcid.org/0000-0003-3107-9519

4 Ahi Evran Üniversitesi, İ̈B Fakültesi, yakkoca38@gmail.com, Orcid ID:orcid.org/ 0000-0002-8772-6896
} 
Podsakoff adapted to Turkish by Cankir was used. The data analyzed with SPSS. As a result of the regression analysis with the communication satisfaction that we defined as the predecessor of the positive voice behavior, it was found that the communication satisfaction explained $79 \%$ of change in the positive voice behavior. To conclude, for the case of hospitals that have intensive and complex organizational structure, the creation of a positive communication climate is recommended as a premise for making the positive voice behaviour, which is considered as a way of achieving a high level of benefits from the employees.

Keywords: Positive voice behaviour, communication satisfaction, organizational communication, hospital employees, communication in hospitals

\section{Giriş}

Örgütlerin amaçlarına ve yönetsel başarıya ulaşmalarında örgüt içi ve örgüt dış1 iletişim faaliyetleri önemli rol oynamakta; örgütsel iletişim, günümüz yenilikçi örgütlerinde örgütsel işleyişin önemli bir parçası olarak önemini giderek artırmaktadır (Bal, 2013: 110; Bitmiş vd., 2014: 58; Steele ve Plenty, 2015: 294). Akkirman ve Harris (2005: 398)'e göre, örgüt içerisinde sık ve yüksek kaliteli bir iletişimin sağlanması, çalışanlar arasında güven ortamının oluşmasını sağlamaktadır. Bu noktada, iş görenlerin örgüt içerisinde mutlu ve huzurlu bir hayat sürdürmeleri amacından yola çıkan, özellikle, iş görenlerin örgütte olumlu davranışlarının gelişimini hedefleyen bir anlayış içerisinde olan pozitif örgütsel davranış akımından bahsetmek yerinde olacaktır. Pozitif örgütsel davranış, pozitif psikoloji yaklaşımına bağlı olarak gelişmiştir ve iş yerinde pozitif psikoloji kapasitesinin kullanılmasını; buna bağlı olarak, iyi olma, memnuniyet ve tatmin gibi anlamlı kişisel duyguları kapsamaktadır (Çalışkan, 2014: 364-365).

Dolayısıyla bu çalışmada ele alınan iletişim doyumu kavramı pozitif bir örgütsel davranış olarak değerlendirilebilecektir. Doyum, bir kimsenin beklentileri karşılandığında ya da daha fazlası elde edildiğinde ortaya çıkan memnuniyet duygusu şeklinde tanımlandığı gibi, genellikle huzurla iliş̧ili bir kavramdır (Gülnar, 2009: 63-64). Bundan dolayı iletişim doyumu, örgüt içi iletişimin sağlıklı olmasına bağlı olarak çalışanlarda oluşan memnuniyet duygusu anlamına gelmektedir (Demirkıran vd., 2013: 324).

Araştırmanın bir diğer ilgi alanını oluşturan çalışan sesliliği (ses çıkartma davranışı) kavramı, Hirschman (1994)'ın çıkış-ses-sadakat modeline dayanmaktadır. Hirschman sesi, memnuniyetsizliğe karşı bir tepki olarak nitelendirmiştir. Örgütsel vatandaşlık davranış1 yazınında ise ses çıkartma davranışı, çalışanların değişiklik için yapıcı önerilerini belirtmek istediklerinde ortaya çıkan bir davranış olarak tanımlanmıştır (Cheng vd., 2013: 83). Ses çıkartma davranışı daha genel ve destekleyici bir ifadeyle örgütün yararına olmak üzere yapılan öneriler olarak belirlenmiştir. Dolayısıyla ses çıkartma davranışı esasında bir iletişim biçimidir (Botero ve Van Dyne, 2009: 87). Ancak ses çıkartma davranışının yalnızca bir iletişim biçimi değil de mevcut olan durumu iyileştirmeyi amaçlayan değişim odaklı bir iletişim biçimi olması istenmektedir (Nikolaou vd., 2008: 667). Bu kapsamda, çalışanların işle ilgili değerli gördüğü politikalar, programlar, hedefler için destek vermeleri ve/veya kurumun gelişimi ve yapılan işlerin daha etkin ve verimli yapılabilmesi için yapıcı öneriler geliştirmeleri ve bunu çeşitli iletişim kanallarıyla; çalışma arkadaşları ve yöneticileriyle gönüllü paylaşmaları pozitif ses çıkartma davranışı olarak adlandırılmaktadır (Çankır, 2016: 3). Ses çıkartma davranışı çeşitli boyutlardan oluşmakla birlikte; bu davranışın, olumlu 
boyutlarının ele alınması ile şekillenen pozitif yönü, bu çalışmanın konusunu oluşturmaktadır.

\section{1. İletişim Doyumu}

İletişim doyumu kavramı, örgütlerin saadeti ve işleyişi açısından önemli bir gösterge olarak ele alınmaktadır. Genel olarak araştırmacılar tarafından etkili ve memnuniyet verici iletişimin; üretkenlik, performans ve müşterilerle uyum açısından örgüte olumlu katk1 sağlayacağı belirtilmektedir (Zwijze-Koning ve Jong, 2007: 263). İletişim doyumu kavramı, iletişim ile memnuniyet arasındaki ilişki üzerine yapılan çok çeşitli araştırmalar sonucunda ortaya çıkmış ve literatürde yaygın olarak kullanılmaya başlanmıştır. Downs ve Hazen, 1977 yılına kadar iletişim doyumu kavramının genel olarak, bir çalışanın toplam iletişim çevresinden algıladığı tek boyutlu genel bir duygu olarak ele alındığını belirtmişlerdir. Ancak, farklı çalışmalarda iletişim doyumunun farklı yönleri olduğu ortaya çıkmıştır (Downs ve Hazen, 1977: 63-64). Dolayısıyla, Downs ve Hazen (1977) çeşitli sorulara cevap vermek ve özellikle iletişim doyumunun tek boyutlu değil de çok boyutlu bir kavram olduğunu ortaya çıkarmak amacıyla kapsamlı bir çalışma yaparak; iletişim doyumu ölçeğini geliştirmişlerdir. Aynı zamanda iletişim doyumunun sekiz temel boyutunu şu şekilde belirlemişlerdir (Downs ve Hazen, 1977: 66-68):

- İletişim İklimi: Bu genel boyut, örgütsel ve bireysel düzeydeki iletişimi yansıtmaktadır. $\mathrm{Bu}$ boyut, çalışanların örgütsel amaçlara ulaşmaları için örgütteki iletişimin çalışanları motive edici ve teşvik edici düzeyi ile sağlıklı olarak algıladıkları iletişim anlayışlarının düzeyi gibi öğeleri içermektedir. Genel olarak, örgütteki iletişimden memnuniyetin geniş çaplı bir ölçümünü bu boyut sağlamaktadır.

- Üstlerle İletişim: Bu boyut çalışanların üstleriyle hem yukarı hem aşağı yönlü iletişiminin boyutlarını içermektedir.

- Örgütsel Bütünleşme: Bu boyut, bireylerin örgütle ve çalışma çevreleriyle ilgili edindikleri bilgilerden memnuniyet düzeylerini kapsamaktadır.

- Araç Kalitesi: Çalışanların, örgütün iletişim kanallarının etkin işleyip işlemediğine yönelik algı düzeylerini yansıtmaktadır. Yani, toplantıların iyi organize edilip edilmediği, örgüt yayınlarının kullanışlı olup olmadığı gibi konularla ilgilenmektedir.

- Yatay ve Biçimsel Olmayan İletişim: Hem yatay hem de biçimsel olmayan (enformel) iletişimle ilgili öğeleri içermektedir. Örgütteki dedikodunun aktiflik düzeyi ile yatay iletişimin doğruluk düzeyi de bu boyutta ölçülmektedir.

- Genel Örgütsel Algı: Bu boyuttaki öğeler, örgütün genel işleyişiyle ilişkili bilgileri yansıtmaktadır. Çalışanların, örgütteki değişimlerle, örgütün finansal durumuyla ve hükümetin örgütü etkileyen faaliyetleriyle ilgili bilgi edinip edinmediği hakkında fikir vermektedir.

- Astlarla İletişim: Bu boyut astlarla hem yukarı hem aşağı yönlü iletişiminin boyutlarını içermektedir.

- Bireysel Geribildirim: Çalışanların bireysel başarıları ve performanslarıyla ilgili iletişim düzeyini yansıtmaktadır. 
Örgütlerdeki iletişim uygulamaları ve iyi kurulmuş karşıllklı iletişimler, bireysel doyum ve iletişim doyumunun öncülleridir (Engin ve Eker Akgöz, 2013: 110-111; Chan ve Lai, 2017: 215). Birçok çalışmada, isteğe bağlı ve olumlu yönelimli sözlü iletişimin ise çalışan ses çıkartma davranışını tanımladığı belirtilmektedir (Morrison vd., 2011: 183; Ward vd., 2016: 1499). Dolayısıyla bu çalışmada iletişim doyumu pozitif ses çıkartma davranışının öncülü olarak ele alınacaktır.

\section{Pozitif Ses Çıkartma Davranışı}

Bilgi paylaşma, serbestçe konuşma ve geribildirim sağlama gibi konulardaki gönülsüzlük çalışanların güven ve motivasyonlarını olumsuz yönde etkileyebilen durumlardır. Aynı zamanda, bilgi ve fikirlerin esirgenmesi; örgütsel karar alma, gelişim ve inovasyon süreçlerini baltalamakta, tüm örgütü olumsuz yönde etkilemektedir. Dolayısıyla pozitif yönde ses çıkartma davranışı bir çok örgüt tarafından olumlu bir davranış olarak kabul edilmekte, özellikle çalışanlarının fikirlerine ihtiyaç duyan örgütler için çok önemli bir davranış haline gelmektedir (Nikolaou vd., 2008: 667). Çünkü örgütlerin, çalışanların örgütün süreç, ürün ve hizmetleri iyileştirmek için üst yönetime sundukları fikir ve görüşler sayesinde rekabetçi avantaj kazanabildikleri anlaşılmıştır (Botero ve Van Dyne, 2009: 84). Bu sebeple, son zamanlarda ses çıkartma davranışı ile ilgili yapılan araştırmaların büyük bir kısmı, ses çıkartma davranışının destekleyici yönlerine odaklanmıştır (Liang vd., 2012: 71).

Van Dyne ve LePine (1998: 109) ses çıkartma davranışını, yalnızca eleştirmekten ziyade iyileştirme amaçlı yapılan, yapıcı bir meydan okuma ifadesi şeklinde ortaya çıkan, destekleyici bir davranış olarak tanımlamaktadırlar. Bu tanıma benzer şekilde Morrison ve diğerleri (2011: 5) de ses çıkartma davranışını, örgütün veya birimin işleyişini iyileştirmek amacıyla fikirlerin, önerilerin ve görüşlerin isteğe bağlı olarak ifade edilmesi olarak açıklamışlardır.

Çalı̧̧anların iş süreçlerini iyileştirmek amaciyla ses çıkartma davranış1 gerçekleştirmesi, grup öğrenme, iyileşmiş iş süreçleri ve inovasyon ve krizlerin önlenmesi gibi pozitif örgütsel sonuçlar doğurmaktadır. Ses çıkartma davranışının örgütsel etkinlik üzerindeki kritik rolünün anlaşılması, araştırmacıların hem kavramsal hem de deneysel olarak ses çıkartma davranışını destekleyen veya engelleyen faktörleri ele almalarına sebep olmaktadır (Liang vd., 2012: 71).

Çalışan ses çıkartma davranışı kavramı ilk olarak Hirschman'ın çıkış-ses-sadakat modelinde ele alınmıştır. Burada, "birey işten kaçınma ve işi terk etme yerine, mevcut sorunun çözümü için mücadeleye girmeli midir?" sorusunun cevabı aranmaktadır (Hirschman, 1994: 272). Daha sonra ses çıkartma davranışı, ekstra rol davranışı veya örgütsel vatandaşlık davranışı kapsamında incelenmiştir (Van Dyne ve LePine, 1998: 109). Kavramı genişleten çalışma ise Maynes ve Podsakoff (2014: 87) tarafindan yapılmış; bu çalışmada ses çıkartma davranışının destekleyici, yapıcı, korumacı ve yıkıcı olmak üzere dört farklı türü tanımlanmış ve ölçek geliştirilmiştir. Bu türlerden destekleyici ve yapıcı ses çıkartma davranışları pozitif ses çıkartma davranışlarının boyutu olarak ele alınmakta ve aşağıdaki gibi tanımlanabilmektedir (Maynes ve Podsakoff, 2014: 91-92):

- Destekleyici Ses Çıkartma: Destekleyici ses çıkartma, işle ilgili değerli görülen politikalar, programlar ve amaçlar gibi faktörlerin desteklendiğinin gönüllü olarak 
ifade edilmesi veya aynı faktörler haksız bir şekilde eleştirildiğinde bunların savunulması için konuşulması olarak tanımlanmaktadır.

- Yapıcı Ses Çıkartma: Yapıcı ses çıkartma, iş ortamındaki organizasyonel işlevsel değişikliği gerçekleştirmeye odaklanmış olan düşüncelerin, bilgilerin veya görüşlerin gönüllü olarak ifade edilmesi olarak tanımlanmaktadır. Bu davranış şeklinde çalışan, işlerin yapılmasıyla ilgili yeni veya iyileştirilmiş yöntemlerin önerisini, var olan çalışma tarzlarıyla sorunları düzeltmenin önerisini veya sorunlar için daha önce tanımlanmış çözümlerin önerisini sunmaktadır.

\section{3. İletişim Doyumu ve Pozitif Ses Çıkartma Davranışı İlişkisi}

Bugünün karmaşık iş çevresi içerisinde örgütler, çalışanlarının fikirlerine ve inovasyonu hızlandıracak düşüncelerine ihtiyaç duymaktadırlar. Özellikle yönetim literatüründe, örgüt içerisinde ses çıkartma davranışının ve iletişim kanallarının gerekliliği sıklıkla vurgulanmaktadır. Yöneticiler her ne kadar fikirlere açık olduklarını belirtseler de, çalışanlar iletişim konusunda cesaretli olamamaktadırlar. $\mathrm{Bu}$ da güven ortamı konusunda sıkıntılar olduğunu düşündürmektedir (Nikolaou vd., 2008: 667; Hsiung, 2012: 349).

Ses çıkartma davranışı literatürde, hem olumlu hem olumsuz yönleriyle son yıllarda sıklıkla çalışılan konulardan biri haline gelmiştir. Ses çıkartma davranışının, lider-üye etkileşimi ile anlamlı ve pozitif yönlü ilişkili olduğu (Botero ve Van Dyne, 2009; Cheng vd., 2013; Palalar Alkan ve Çankır, 2016); otantik liderlik ile ses çıkartma davranışının bir arada incelendiği bir çalışmada, adalet iklimi, pozitif ruh hali ve lider-üye etkileşiminin aracılık rolünün ses çıkartma davranışı ile güçlü bir bağ oluşturduğu (Hsiung, 2012), yöneticiye güvenin ses çıkartma davranışını olumlu yönde etkilediği (Gao vd., 2011) ve bu ilişkide psikolojik rahatlığın aracılık rolü olduğu (Derin, 2017); yine pozitif psikoloji alanında önemli bir başlık olarak kabul edilen psikolojik rahatlık algısı ile ilgili yapılan bir çalışmada, psikolojik rahatlık algısının ses çıkartma davranışı ile takım işbirliği arasında aracı değişken rolüne sahip olduğu (Yener, 2017) ortaya çıkarılmıştır. Ses çıkartma davranışının özellikle pozitif boyutunu ele alan çalışmalardan Çankır (2016)'ın çalışmasında ise, pozitif ses çıkartma davranışı, lider-üye etkileşimi ve örgütsel güven değişkenleri arasında anlamlı ve pozitif bir ilişki olduğu anlaşılmaktadır.

Şimdiye kadar yapılan çalışmaların genellikle çalışanların ses çıkartma davranışları ve liderleriyle ilgili algılarını ele aldığı görülmektedir. Liderlerin çalışanlarıyla gerçekte nasıl iletişim kurdukları konusu, bir başka deyişle somut iletişim süreçleri konusunda literatürde boşluk bulunmaktadır. İletişimin, lider-üye etkileşimini şekillendiren ve böylece çalışanların kendilerini lidere emanet edip etmeyeceklerini ve ses çıkartma davranışı gösterip göstermeyeceklerini belirleyen en önemli faktör olduğu düşünüldügünde bu konu, ele alınması gereken bir konu olarak görülmektedir (Weiss vd., 2017: 3).

İletişim doyumu ile ilgili yapılan literatür taraması sonucunda iletişim doyumunun, iş tatmini (Downs ve Hazen, 1977; Steele ve Plenty, 2015; Yalım, 2015), örgüt kültürü (Eroğlu ve Özkan, 2009), örgütsel bağl1lık (Engin ve Eker Akgöz, 2013; Kant ve Balc1 Akpınar, 2017), örgütsel özdeşleşme (Derin ve Tuna, 2017), algılanan adalet ve örgütsel vatandaşlık davranışı (Chan ve Lai, 2017) gibi birçok farklı değişkenle ilişkili olduğu anlaşılmaktadır. Ancak, ilişkili kavramlar olmalarına rağmen pozitif ses çıkartma davranışı ile iletişim doyumu ilişkisini inceleyen araştırmalara rastlanılmamıştır. 
Hem lider-üye etkileşimi kavramı içerisinde bir iletişim boyutu bulunduğu (Fairhurst, 1993; Fix ve Sias, 2006), hem de örgüt içerisindeki kaliteli bir iletişimin güven ortamı oluşturduğu anlaşılmaktadır (Akkirman ve Harris, 2005). Aynı zamanda lider-üye etkileşiminin aracılık rolünün ses çıkarma davranışı ile güçlü bir bağ oluşturduğu (Hsiung, 2012) ve yöneticiye duyulan güvenin ses çıkarma davranışını olumlu yönde etkilediği (Gao vd., 2011; Derin, 2017) de bilinmektedir. Buradan yola çıkıldığında, iletişim güven ortamı oluşturmakta, güven de ses çıkartma davranışını olumlu yönde etkilemektedir. O halde iletişim doyumunun, pozitif ses çıkartma davranışının öncülü olduğu öngörülmekte, bu sebeple pozitif ses çıkartma davranışını olumlu yönde etkileyeceği beklenmektedir. $\mathrm{Bu}$ çalışmada, iletişim doyumu ve pozitif ses çıkartma davranışı ele alınarak, literatürdeki boşluğu doldurmak amacıyla aşağıdaki hipotez geliştirilmiştir:

H1: İletişim doyumu, pozitif ses çıkarma davranışını olumlu yönde etkiler.

\section{Araştırmanın Yöntemi}

$\mathrm{Bu}$ araştırma betimsel nitelikte, kesitsel bir alan araştırması olarak planlanmıştır. Araştırmanın amacı, iletişim doyumunun pozitif ses çıkartma davranışının bir öncülü olup olmadığını belirlemek ve bununla birlikte pozitif örgütsel davranış literatürüne katkı sağlamaktır. Bu amaçla, araştırmanın evrenini, Kırşehir merkezde hizmet veren Ahi Evran Üniversitesi Eğitim ve Araştırma hastanesindeki 1100 çalışan oluşturmaktadır. Çalışma kapsamında ayrıca bir örneklem seçimi yapılmamış olup, araştırmaya katılmayı kabul eden toplam 223 çalışana anket uygulanmıştır.

Katılımcıların örgütsel düzeyde sergilediği tutumların belirlenmesi amacıyla geçerlilik ve güvenirlik çalışmaları yapılmış ölçekler kullanılmıştır. Çalışanların iletişim doyum düzeylerini tespit etmek amaciyla Downs ve Hazen (1977) tarafından geliştirilen ve Bal (2013) tarafından Türkçe 'ye uyarlanan "İletişim Doyum Ölçeği”" (The Communication Satisfaction Questionnaire) kullanılmış, ölçeğin bu çalışmada Cronbach Alfa katsayısı 0,981 olarak bulunmuştur. Çalışmada kullanılan iletişim doyumu ölçeği, 5'li likert tipi ölçek olup, beş alt boyuttan ve her bir boyuta ait 5 sorudan oluşmaktadır.

Pozitif ses çıkartma düzeylerini belirlemek amacıyla, Maynes ve Podsakoff (2014) tarafından geliştirilen ve Çankır (2016) tarafından Türkçe uyarlaması yapılan "Pozitif Ses Çıkartma Ölçeği" kullanılmış, ölçeğin bu çalışmada Cronbach Alfa katsayısı 0,920 olarak bulunmuştur. Araştırmada elde edilen nicel verilerin analizi için ayrı bilgisayar destekli analiz programı (SPSS) kullanılmış, araştırma hipotezleri test edilmiştir.

\section{Bulgular ve Tartışma}

$\mathrm{Bu}$ bölümde, araştırma grubuna ait verilerin analizlerine ilişkin istatistikler verilerek tartışılmışıır. Araştırmaya katılanların sosyo-demografik özellikleri, kurum içi motivasyonu yeterli bulma durumları ve yöneticilik görevlerinin olup olmadı̆̆ Tablo 1'de sunulmuştur.

Tablo 1. Araştırma grubuna ait bazı özelliklere ilişkin dağılım

\begin{tabular}{llllll}
\hline Değişkenler & f & $\%$ & Değişkenler & f & $\%$ \\
\hline
\end{tabular}




\begin{tabular}{|c|c|c|c|c|c|}
\hline \multicolumn{3}{|l|}{ Cinsiyet } & \multicolumn{3}{|l|}{ Kurum İçi Motivasyonu Yeterli } \\
\hline Kadın & 123 & 55,2 & Bulma & 102 & 45,7 \\
\hline Erkek & 100 & 44,8 & Evet & 121 & 54,3 \\
\hline TOPLAM & 223 & 100,0 & Hayır & 223 & 100,0 \\
\hline & & & TOPLAM & & \\
\hline Yaş & & & Yöneticilik Görevi Olup Olmadığı & & \\
\hline 25 yaş ve altı & 48 & 21,5 & Var & 60 & 26,9 \\
\hline $26-30$ & 63 & 28,2 & Yok & 163 & 73,1 \\
\hline 31-35 & 48 & 21,5 & TOPLAM & 223 & 100,0 \\
\hline $36-40$ & 30 & 13,5 & & & \\
\hline 41-45 & 4 & 1,8 & & & \\
\hline 46-50 & 10 & 4,5 & & & \\
\hline 51 ve üzeri & 20 & 9,0 & & & \\
\hline TOPLAM & 223 & 100,0 & & & \\
\hline
\end{tabular}

Araştırmaya katılanlardan, \%55,2'si kadın, \%44,8'i ise erkektir. \%28,3'lük oranla 26-30 yaş aralığındaki işgörenler çoğunluğu oluşturmaktadır. Ayrıca katılımcılardan $\% 73,1$ 'nin herhangi bir yönetim görevi bulunmamakla beraber, \%54,3'ü kurum içi motivasyonu yeterli bulmadığını belirtmiştir (Tablo 1).

Araştırma grubunun iletişim doyumu ve pozitif ses çıkarma puanlarına ait ortalamalar Tablo 2'de verilmiştir.

Tablo 2. Araştırma grubuna ait iletişim doyumu ve pozitif ses çıkartma puanlarına ilişkin

\begin{tabular}{|c|c|c|c|}
\hline & $\mathbf{x}$ & ss & $\mathbf{n}$ \\
\hline İletişim İklimi & 15,0090 & 5,91531 & 223 \\
\hline Yatay İletişim & 15,4215 & 6,12644 & 223 \\
\hline Üstlerle İletişim & 15,3946 & 6,44774 & 223 \\
\hline Kurumsal Bütünleşme & 15,6682 & 6,38320 & 223 \\
\hline Kurumsal Geribildirim & 15,1480 & 5,80622 & 223 \\
\hline Pozitif Ses Çıkartma Puanı & 31,1973 & 11,99086 & 223 \\
\hline
\end{tabular}

Araştırma grubunun iletişim doyum alt boyutları ve pozitif ses çıkartma davranışı puanlarının dağılımının verildiği Tablo 2'ye göre katılımcıların en fazla doyum sağladığ iletişim doyumu boyutu kurumsal bütünleşme $(\chi=15,6682)$ iken, bunu sirasiyla yatay iletişim $(\chi=15,4215)$, üstlerle iletişim $(\chi=15,3946)$ ve kurumsal geribildirim $(\chi=15,1480)$ izlemektedir. İletişim iklimi $(\chi=15,0090)$ diğerlerine göre daha düşük düzeydedir.

Korelasyon analizi, iki veya daha fazla değişken arasındaki ilişkiyi ifade etmekle beraber; değişkenler arasındaki ilişkinin yönü ve bu ilişkinin kuvvetini de belirlemeye yardımcı olur (Gürbüz ve Şahin, 2016: 264-265). Yapılan korelasyon analizleri sonucunda, iletişim doyumunun boyutları olan; iletişim iklimi, yatay iletişim, üstlerle iletişim, kurumsal bütünleşme ve kurumsal geribildirim ile pozitif ses çıkartma davranışı arasında yüksek düzeyde pozitif ilişki tespit edilmiştir (Tablo 3 ).

Tablo 3. Pozitif ses çıkartma ile iletişim doyumu ilişkisine yönelik korelasyon analizi 


\begin{tabular}{|c|c|c|c|c|c|c|}
\hline & 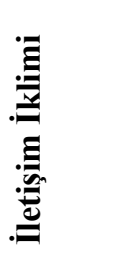 & 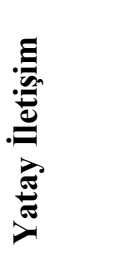 & 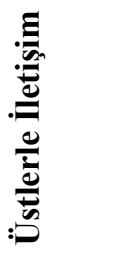 & 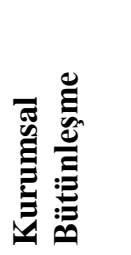 & 焉昜 & 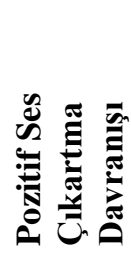 \\
\hline İletişim İklimi & 1 & & & & & \\
\hline Yatay İletişim & $0,892^{* *}$ & 1 & & & & \\
\hline Üstlerle İletişim & $0,835^{* *}$ & $0,828^{* *}$ & 1 & & & \\
\hline $\begin{array}{l}\text { Kurumsal } \\
\text { Bütünleşme }\end{array}$ & $0,850^{* *}$ & $0,879^{* *}$ & $0,864^{* *}$ & 1 & & \\
\hline $\begin{array}{l}\text { Kurumsal } \\
\text { Geribildirim }\end{array}$ & $0,840^{* *}$ & $0,841^{* *}$ & $0,847^{* *}$ & $0,858^{* *}$ & 1 & \\
\hline $\begin{array}{l}\text { Pozitif Ses } \\
\text { Çıkartma } \\
\text { Davranışı }\end{array}$ & $0,863^{* *}$ & $0,858^{* *}$ & $0,785^{* *}$ & $0,840^{* *}$ & $0,854^{* *}$ & 1 \\
\hline
\end{tabular}

Korelasyon katsayısı 0,7 ile 1 arasında değerler aldığında, değişkenler arasında kuvvetli bir ilişki olduğu söylenebilmektedir (Gürbüz ve Şahin, 2016: 264-265). Buna göre, Tablo 3'te verilen analiz sonuçlarından, iletişim iklimi, yatay iletişim, üstlerle iletişim, kurumsal bütünleşme ve kurumsal geribildirim ile pozitif ses çıkartma davranışı arasında anlamlı ve yüksek düzeyde pozitif yönlü ilişki tespit edilmiştir.

İyi bir örgüt iklimi oluşturmanın çalışan ses çıkartma davranışını iyileştirecek önemli bir etken olduğu daha önceki çalışmalarda ortaya çıkmıştır (Tang, 2015: 402). İletişim iklimi, örgüt ikliminin bir boyutu olup çalışmamız daha önceki çalışmaları desteklemektedir. Hsiung (2012) ise çok boyutlu bir çalışma yapmış ve usul adaleti ikliminin düzenleyici rolü doğrultusunda, pozitif ruh hali ve lider üye etkileşimi kalitesinin ses çıkartma davranışı ile güçlü bir bağ kurduğunu tespit etmiştir. Lider üye etkileşimin kalitesini belirleyici unsurlardan biri olarak üstlerle iletişim düşünüldüğünde, önceki çalışmaların bu çalışmada ortaya çıkan korelasyon analizi sonuçlarını teyit ettiği görülmektedir.

Tablo 4. Pozitif ses çıkartmanın iletişim doyumuna etkisine ait regresyon analizi sonuçları

\begin{tabular}{|c|c|c|c|c|c|}
\hline $\mathbf{r}$ & $\mathbf{r}^{2}$ & Düzeltilmiş $\mathbf{r}^{2}$ & Standart Hata & f & Sig. \\
\hline $0,893^{\mathrm{a}}$ & 0,798 & 0,797 & 5,40708 & 870,763 & $0,000^{\mathrm{b}}$ \\
\hline \multirow[t]{2}{*}{ Model 1} & $\begin{array}{c}\text { Standardize } \\
\text { edilmemiş } \\
\text { katsayılar }\end{array}$ & $\begin{array}{l}\text { Standardize } \\
\text { edilmiş } \\
\text { katsayılar }\end{array}$ & & & \\
\hline & $\mathbf{b}$ & Standart Hata & Beta & $\mathbf{t}$ & $\mathbf{p}$ \\
\hline \multirow{2}{*}{$\begin{array}{c}\text { Constant } \\
\text { İletişim } \\
\text { Doyumu }\end{array}$} & 2,726 & 1,031 & \multirow{2}{*}{0,893} & 2,645 & 0,009 \\
\hline & 0,371 & 0,013 & & 29,509 & 0,000 \\
\hline
\end{tabular}

(Bă̆ımlı Değişken: Pozitif Ses Çıkartma; Durbin-Watson: 1,998)

Pozitif ses çıkartma davranışının öncülü olarak nitelendirdiğimiz iletişim doyumu ile yapılan regresyon analizi sonucunda iletişim doyumunun, katılımcıların pozitif ses çıkartma 
davranışındaki \%79'luk değişimi açıkladığı tespit edilmiştir $\left(\mathrm{r}^{2}=0,798 ; \mathrm{f}=870,763, \mathrm{p}=0,000\right)$ (Tablo 4). Yapılan analizde $\mathrm{f}(\mathrm{f}=870,763$, p: 0,000$)$ değeri anlamlı bulunduğu için pozitif ses çıkartma davranışını iletişim doyumu ile açıklamaya çalıştı̆̆ımız modelimiz anlamlı bir model olup, iletişim doyumundaki bir birimlik artış pozitif ses çıkartma davranışını 0,371 birim artıracaktır. Ayrıca t değeri de anlamlı bulunduğu için $(\mathrm{p}=0.000)$ iletişim doyumuna ait katsayı anlamlıdır. Modelin tahmini sonucu ise;

[Pozitif Ses Çıkartma Davranışı = 2,726+0,371xiletişsim Doyumu] şeklinde olacaktır.

Tablodan, değişkenler arasında pozitif yönlü ve kuvvetli bir ilişki olduğu anlaşılmaktadır $(r=0,89)$. Analiz sonuçlarına göre, iletişim doyumunun pozitif ses çıkartma davranışını olumlu yönde etkilediği, bu sebeple pozitif ses çıkartma davranışının öncülü olduğu anlaşılmaktadır. Buna göre H1 hipotezi desteklenmiştir.

\section{Sonuç ve Öneriler}

$\mathrm{Bu}$ çalışma iletişim doyumu ile pozitif ses çıkartma davranışı arasındaki ilişkinin belirlenmesi açısından ulaşılan literatür içerisindeki ilk araştırma olup, literatürdeki boşluğu doldurması açısından önem arz etmektedir. Weiss ve diğerlerine (2017) göre, iletişim, liderüye etkileşimini şekillendiren ve böylece çalışanların kendilerini lidere emanet edip etmeyeceklerini ve ses çıkartma davranışı gösterip göstermeyeceklerini belirleyen en önemli faktördür ve bu konu, ele alınması gereken bir konu olarak görülmektedir. Dolayısıyla bu çalışma, sonuçları itibariyle bundan sonra gelecek olan çalışmalara yol gösterici olması açısından da önem arz etmektedir. Bu çalışmaya göre iletişim doyumu ses çıkartma davranışının bir öncülü olarak ortaya çıkmaktadır ve örgütlerde iletişim doyumuna önem verilmesi gerektiği ortaya çıkmaktadır. Bununla birlikte araştırma sonucunda, yoğun ve karmaşık bir örgüt yapısına sahip hastanelerde, örgütün çalışanlardan yüksek düzeyde fayda sağlamasının bir yolu olarak düşünülen pozitif ses çıkartma davranışının, bir örgüt kültürü haline getirilmesinin öncülü olarak; olumlu iletişim ikliminin yaratılması önerilmektedir. Yatay ve dikey iletişim düzeylerinde açıklık ve yalınlık, kurumsal bütünleşme ve geribildirim düzeyinde artış sağlanması önerilen diğer hususlardır. Aynı zamanda güven konusu ele alınan iki değişken açısından da önem arz etmektedir. Bir sonraki çalışmada, iletişim doyumu ve pozitif ses çıkarma ilişkisinde güvenin aracı rolünün ele alınması önerilmektedir.

Her çalışmada olduğu gibi bu çalışmada da bir takım kısıtlar bulunmaktadır. Araştırmanın evrenini zaman ve maliyet gibi sebeplerle, Kırşehir merkezde hizmet veren Ahi Evran Üniversitesi Eğitim ve Araştırma Hastanesi'ndeki çalışanlar oluşturmakla birlikte; örneklemimiz araştırmaya katılmayı kabul eden toplam 223 çalışanla sınırlıdır. Bu durum araştırma sonuçlarının genellenebilirliğini güçleştirmektedir. Bundan sonraki çalışmalarda, farklı hizmet sektörlerinin ve farklı illerin hedef alınması konuyla ilgili sonuçların genellenebilmesi bakımından daha faydalı olacaktır.

\section{Kaynakça}

Akkirman, A.D. ve Harris, D.L. (2005). "Organizational Communication Satisfaction in The Virtual Workplace”, Journal of Management Development, 24(5): 397-409. 
Bal, C.G. (2013). "Sağlık Kurumlarında İletişim Doyumu Üzerine Bir Alan Araştırması", Selçuk Üniversitesi İktisadi ve İdari Bilimler Fakültesi Sosyal ve Ekonomik Araştırmalar Dergisi, 13(25): 107-125.

Bitmiş, M.G., Güney, S. ve Demirel, H. (2014). "İletişim Doyumu Verimlilik İlişkisinde Örgütsel Bağlılık ve İş Tatmininin Rolü: Çoklu Aracılı Bir Model Testi”, H.Ü. İktisadi ve İdari Bilimler Fakültesi Dergisi, 32(2): 57-74.

Botero, I.C. ve Van Dyne, L. (2009). "Employee Voice Behaviour: Interactive Effects of LMX and Power Distance in the United States and Colombia", Management Communication Quarterly, 23(1): 84-104.

Chan, S.H.J. ve Lai, H.Y.I. (2017). "Understanding The Link Between Communication Satisfaction, Perceived Justice and Organizational Citizenship Behavior", Journal of Business Research, 70: 214-223.

Cheng, J., Lu, K., Chang, Y. ve Johnstone, S. (2013). "Voice Behavior and Work Engagement: The Moderating Role of Supervisor-Attributed Motives", Asia Pacific Journal of Human Resources, 51: 81-102.

Çalışkan, S. C. (2014). "Pozitif Örgütsel Davranış Değişkenleri ile Yeni Araştırma Modelleri Geliştirme Arayışları: Pozitif Örgütsel Davranış Değişkenlerinin İşe Adanmışlık, Tükenmişlik ve Sinizm Üzerine Etkileri ve Bu Etkileşimde Örgütsel Adalet Algısının Aracılık Rolü Üzerine Bir Araştırma”, Dokuz Eylül Üniversitesi Sosyal Bilimler Enstitüsü Dergisi, 16(3): 363-382.

Çankır, B. (2016). "Çalışanlarda Pozitif Ses Çıkartma Davranışı Nasıl Oluşur? Örgütsel Güven, Psikolojik Sözleşme İhlali, Lider-Üye Etkileşimi ile Pozitif Ses Çıkartma Davranışı Arasındaki İlişkinin İncelenmesi”, Kırklareli Üniversitesi İktisadi ve İdari Bilimler Fakültesi Dergisi, 5(2): 1-12.

Demirkıran, M., Dikmetaş Yardan, E. ve Yorulmaz, M. (2013). "İl Sağlık Müdürlüğü Çalışanlarının Örgütsel Adalet Algılamalarının İletişim Doyumlarına Olan Etkisi”, Sosyal ve Beşeri Bilimler Dergisi, 5(2): 322-334.

Derin, N. (2017). "Işsyerinde Kişiler Arası Güven ile İşgören Sesliliği Arasındaki İlişskide Psikolojik Rahatlığın Aracılık Rolü”, Yönetim Bilimleri Dergisi, 15(30): 51-68.

Derin, N. ve Tuna, H. (2017). "Akademik Bir Örgütte İletişim Doyumunun Örgütsel Özdeşleşmeye Etkisi”, Selçuk İletişim, 9(4): 119-128.

Downs, C.W. ve Hazen, M.D. (1977). "A Factor Analytic Study of Communication Satisfaction", The Journal Of Business Communication, 14(3): 63-73.

Engin, E. ve Eker Akgöz, B. (2013). "The Effect of Communication Satisfaction on Organizational Commitment, British Journal of Arts and Social Sciences", 14(II): 109124.

Eroğlu, E. ve Özkan, G. (2009). “'Örgüt Kültürü’ ve 'İletişim Doyumu’ ile Bireysel Özellikler Arasındaki İlişkinin Değerlendirilmesi: Bir Uygulama Örneği”, Selçuk İletişim, 5(4):50-61.

Fairhurst, G. T. (1993). "The Leader-Member Exchange Patterns of Women Leaders in Industry: A Discourse Analysis", Communication Monographs, 60(4): 321-351.

Fix, B. ve Sias, P. M. (2006). "Person-Centered Communication, Leader-Member Exchange, and Employee Job Satisfaction", Communication Research Reports, 23(1): 35-44.

Gao, L., Janssen, O. ve Shi, K. (2011). "Leader Trust and Employee Voice: The Moderating Role of Empowering Leader Behaviors", The Leadership Quarterly, 22: 787-798.

Gülnar, B. (2009). "İletişim Doyumu Boyutları ile Örgütlenme Yapısı İlişkisi: Selçuk Üniversitesi Akademisyenleri Örneği”, Selçuk İletişim, 5(4): 62-82. 
Gürbüz, S. ve Şahin, F. (2016). Sosyal Bilimlerde Araştırma Yöntemleri: Felsefe-YöntemAnaliz, Ankara: Seçkin Yayıncılık.

Hirschman, A.O. (1994). "Excerpt from Chapter Eight; Exit, Voice and Loyalty: Responses to Decline in Firms, Organizations and States", The Social Contract Press, 4(4): 272-275.

Hsiung, H. (2012). "Authentic Leadership and Employee Voice Behavior: A Multi-Level Psychological Process", Journal of Business Ethics, 107: 349-361.

Kant, E. ve Balcı Akpınar, R. (2017). "Hemşirelerin İletişim Doyumu ve Örgütsel Bağlılıkları Arasındaki İlişki”, Atatürk İletişim Dergisi, 14: 203-215.

Liang, J., Farh, C.I.C. ve Farh, J. (2012). "Psychological Antecedents of Promotive and Prohibitive Voice: A Two-Wave Examination", Academy of Management Journal, 55(1): 71-92.

Maynes, T.D. ve Podsakoff, P.M. (2014). "Speaking More Broadly: An Examination of the Nature, Antecedents, and Consequences of an Expanded Set of Employee Voice Behaviors", Journal of Applied Psychology, 99(1): 87-112.

Morrison, E.W., Wheeler-Smith, S.L. ve Kamdar, D. (2011). "Speaking Up in Groups: A Cross-Level Study of Group Voice Climate and Voice", Journal of Applied Psychology, 96(1): 183-191.

Nikolaou, I., Vakola, M. ve Bourantas, D. (2008). "Who speaks up at work? Dispositional Influences on Employees' Voice Behavior", Personnel Review, 37(6): 666-679.

Palalar Alkan, D. ve Çankır, B. (2016). "Lider Üye Etkileşiminin Pozitif Ses Çıkartma Davranışı Üzerindeki Etkisinde Dağıtım Adaletinin Aracılık Etkisi”, TURAN-SAM Uluslararas1 Bilimsel Hakemli Dergisi, 8(32): 472-481.

Steele, G.A. ve Plenty, D. (2015). "Supervisor-Subordinate Communication Competence and Job and Communication Satisfaction", International Journal of Business Communication, 52(3): 294-318.

Tang, M. (2015). "How to Enhance Employee Voice Behavior Based on Game Theory", Modern Economy, 6: 398-403.

Van Dyne, L. ve LePine, J.A. (1998). "Helping and Voice Extra-Role Behaviors: Evidence of Construct and Predictive Validity", Academy of Management Journal, 41(1): 108-119.

Ward, A., Ravlin, E. C., Klaas, B. S., Ployhart, R. E. ve Buchan, N. R. (2016). "When Do High Context Communicators Speak Up? Exploring Contextual Communication Orientation and Employee Voice", American Psychological Association, 101(10): 14981511.

Weiss, M., Kolbe, M., Grote, G., Spahn, D.R. ve Grande, B. (2017). "We Can Do It! Inclusive Leader Language Promotes Voice Behavior In Multiprofessional Teams", The Leadership Quarterly, Article in press.

Yalım, F. (2015). "Mavi Yakalı Çalışanlarda İletişim Doyumu ile İş Tatmini Arasndaki İlişkinin İncelenmesi: Esaktif Tekstil Çalışanları Üzerine Bir Araştırma", Erciyes İletişim Dergisi Akademia, 4(2): 124-140.

Yener, S. (2017). "Psikolojik Rahatlık Algısının İşgören Sesliliği ve Takım İşbirliği Arasındaki İlişkide Aracı Değişken Rolü”, Dokuz Eylül Üniversitesi Sosyal Bilimler Enstitüsü Dergisi, 19(2): 187-204.

Zwijze-Koning, K. ve Jong, M.D. (2007). "Evaluating the Communication Satisfaction Questionnaire as a Communication Audit Tool", Management Communication Quarterly, 20(3): 261-282. 